\title{
Impact Response and Damage Characteristics of Carbon Fiber Reinforced Aluminum Laminates Under Low Velocity Impact Loading
}

\author{
Khalid M. Algadah, Abdulaziz S. Alaboodi
}

\begin{abstract}
CARALL hybrid material has been extensively used in the aircraft structure due to their competitive impact strength. Low velocity impact test is utilized to evaluate the impact and damage properties for such material. It is also employed to observe complex damage mechanisms. A numerical modelling is an alternative way for impact assessment. This paper investigates the impact and damage properties under low velocity impact using numerical modeling and experimental work. A three-dimensional (3D) finite element (FE) model was devolved and validated with two studies from the literature. This model was meshed with solid elements. It was subjected to $2.4 \mathrm{~m} / \mathrm{s}$ impact velocity and to $10 \mathrm{~J}$ impact energy. Absorbed energy, penetration, impact load and damage morphology were obtained. The impact energy was efficiently absorbed by the material. Both aluminum alloy layers underwent plastic deformation whereas the fiber layer failed. A macroscopic cross-sectional morphology was presented using the FE model. An agreement between the numerical and the experiment results were achieved and discussed.

Keywords: Impact properties; Damage characteristics; Carbon fiber reinforced aluminum laminate (CARAL); Fiber metal laminates (FMLs); Low velocity impact (LVI).
\end{abstract}

\section{INTRODUCTION}

As a result of the improvement and development in the aircraft industry in terms of performance and weight saving, the fiber meatal laminates (FMLs) progress was widely noticed. FMLs is a novel material used in aircraft applications due to their unique mechanical properties under impact, flexure and tensile events [1]. Delft University has developed FMLs to withstand fatigue loading. The most common used FMLs are carbon fibers reinforced aluminum laminate (CARALL) which is based on carbon fiber, glass fiber reinforced aluminum laminate (GLARE) based on fiber glass, and aramid fiber reinforced aluminum laminate (ARALL) based on aramid fibers. CARALL is constructed from multiple carbon fiber plies bonded together with aluminum plies. Aircraft wing and fuselage are typically made form GLARE. The upper fuselage sheet is built from GLARE

Revised Manuscript Received on April 21, 2020.

* Correspondence Author

Abdulaziz S. Alaboodi*, Department of Mechanical Engineering, College of Engineering, Qassim University, Saudi Arabia, Saudi Arabia. Email: alaboodi@qec.edu.sa

Khalid M. Algadah, Department of Mechanical Engineering, College of Engineering, Qassim University, Saudi Arabia, Saudi Arabia. Email: kmgadah@gmail.com

(C) The Authors. Published by Blue Eyes Intelligence Engineering and Sciences Publication (BEIESP). This is an open access article under the CC BY-NC-ND license (http://creativecommons.org/licenses/by-nc-nd/4.0/) which consequently save $794 \mathrm{~kg}$ of the Airbus A380 weight [2]. FMLs afford substantial impact resistance, high fracture toughness, energy absorption capability, moisture resistance, weight savings, low density, corrosion resistance, fire resistance, and less repair and less maintenance cost and time [3]. There are different types of failure modes occur in CARALL material. For example, interfacial debonding and inter-laminar delamination, fiber breakage, matrix cracking, metal cracking and fiber pull out are all damage forms. Fiber bridging effect arrest the crack instigation and propagation in FMLs [4]. A compressive force on FMLs causes delamination buckling. Delamination zone propagation and layer buckling diminishes the residual strength [5]. Specific penetration energy of CARALL composite laminates declines when the thickness increases [6]. In [7] GLARE 5-2/1-0.3 was fabricated and tested with repetitive impact loading under low velocity regime. This FMLs shows outstanding impact resistance attributed to the aluminum layers which arrest the delamination evolution. Pervasive delamination and several matrix cracking occur in carbon fiber reinforced epoxy subjected to low velocity impact loading [8]. GALRE impact resistance was compared with aluminum and carbon / polyetherimide (PEI) laminates [9]. GLARE provides optimal properties for instance, significant residual strength, impact, fatigue and corrosion resistance. The internal degradation and plastic defamation which occur during FMLs impact damage is very complex mechanisms [10]. Moreover, Kevlar layers, for example, when it hybridize with S-glass fiber its impact strength and absorbed energy increase. This happens when the impact force subjected toward the Kevlar layers side [11]. It was found that zero alignment of the Kevlar fibers and glass fibers could offer sustainable outcomes in terms of modulus of elasticity value under tensile strength [12]. When the fiber plies are oriented in the loading direction, they provide high tensile strength, yield strength and modulus of elasticity [13]. Many AL2024 layers were utilized for GLARE laminates allowed for superlative residual and blunt notch strength as well as impact and fatigue resistance [14].

Finite element analysis (FEA) can simulate the impact behavior of CARALL composite laminates. Macroscopic and mesoscopic are two approaches widely used for composite materials simulation subjected to impact loading $[15,16]$. With regard to failure criteria the element stiffness declines once it fails. Convergence and instability issues arise during simulation as a result of element distortion caused by stiffness reduction [17].

Complex damage mechanisms are observed using numerical simulation.

Blue Eyes Intelligence Engineering \& Sciences Publication 
This paper presents an advanced 3D finite element model used for evaluating of CARALL impact and damage properties under low velocity impact. This model was tested and validated with two studies from the literature. They were named as CARALL 1 as for the numerical model of this study, CARALL 2 for [18] experiment and CARALL 3 for [19] work. It was meshed with connivant nods and elements until it provided meaningful results. It was exposed to $2.4 \mathrm{~m} / \mathrm{s}$ impact velocity and to $10 \mathrm{~J}$ impact energy. The outcomes properties were: absorbed energy, maximum penetration, maximum impact load, fiber brakeage and delamination. The numerical model was validated with related studies.

\section{EXPERIMENT SETUP}

The test procedure and material fabrication method of the specimen were adopted form Rajan et al. experimentation [18]. It was considered to be consistent with its geometry and impact parameters values in order to get the numerical model validated thereafter.

\section{A. Material fabrication}

The sample was made from unidirectional carbon fiber fabric 300 gsm weight blended with $0.3 \mathrm{~mm}$ two aluminum sheets. For more effective joining condition between layers, ASTM D 2674 and ASTM D 2651 standards were employed. The carbon fiber ply was oriented in $0^{\circ}$ direction. The sample was manufactured using hand layup method. The carbon fiber layer was impregnated into the aluminum layers. An Epotec YD mixed with hardener triethylenetetramine (TETA) was used as a resin. It was wiped between the metal and fiber layers. The sample was cut and machined in a rectangular shape according to $150 \mathrm{~mm}$ x $100 \mathrm{~mm}$ ASTM standards. Figure 1 illustrates the schematic drawing of 2/1 CARALL.

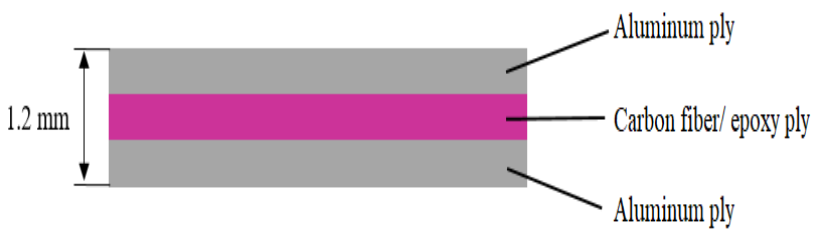

Fig. 1.Schematic diagram of 2/1 CARALL

\section{B. Impact test}

Low velocity impact test was performed on a CARALL 2/1 sample. Figure 2 shows the drop tower apparatus used for impact test. ASTM D 7136 standard was followed. Four samples were tested in [18] to obtain more accurate results. The impactor velocity was specified $2.4 \mathrm{~m} / \mathrm{s}$ which correspond to $10 \mathrm{~J}$. The impactor was left up to $500 \mathrm{~mm} .2 .5$ $\mathrm{kg}$ loads were added onto the machine cross head.

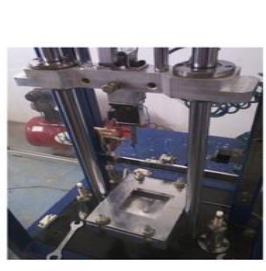

(a)

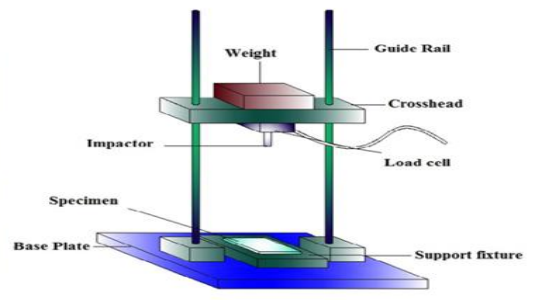

(b)
Fig. 2.(a) Drop tower machine, and (b) its schematic drawing [18].

\section{NUMERICAL SIMULATION}

The test procedure and material fabrication method of the

\section{A. Finite element analysis}

3D model was developed and simulated using finite element analysis. There are different types of nodes and elements generally used in finite element analysis. They are illustrated in figure 3. For bar and truss components one-dimensional nodes and element are used. Two-dimensional nodes and element are utilized for 2D problem such as plain stress and plain strain. Thus, for CARALL model 3D hexahedral elements were dominantly used.

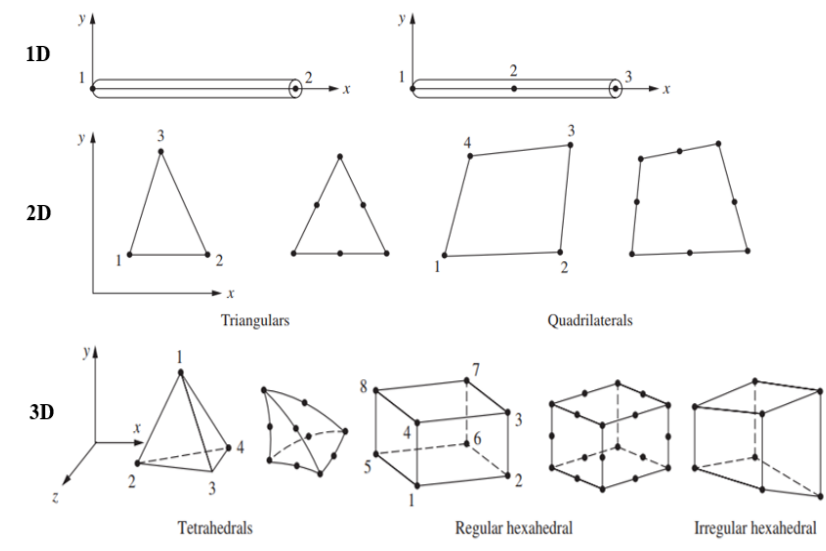

Fig. 3.Nodes and elements types in FEA [21]

There are two approaches based on geometry size can be followed for model simulation. They are called macroscopic and mesoscopic simulation. Macroscopic scale does not observe more details such as, wrap and weft yarns interaction. They are considered as one object having orthotropic mechanical properties. In this simulation, shell elements are employed. This is consequently reducing the simulation time. On the other hand, mesoscopic approach can simulate more detail mechanisms, but it consumes more computational cost and time $[15,16]$. Hashin's failure criteria and elastic-plastic property would simulate the aluminum layers of the fiber metal laminates under the low velocity impact successfully [20]. Composite layer under an impact loading is computed using the following equations [22]:

$$
\begin{gathered}
\{P\}=[K]\{d\}+[C]\{\dot{d}\}+[M]\{\ddot{d}\} \\
{[K]=t A[B]^{T}[D][B]}
\end{gathered}
$$

Where, $\{P\}$ is the impact force, $[K]$ is the stiffness matrix, $\{d\}$ is the displacement matrix, $\{\dot{d}\}$ is the velocity matrix, $\{\ddot{d}\}$ is the acceleration matrix, $[M]$ is the mass matrix, $[C]$ is the damping matrix, $[B]$ is geometric properties matrix , $[D]$ is the material property matrix, $A$ is the layer area and $t$ is layer thickness. In addition , material property matrices of isotropic and orthotropic materials are assigned according to Hooke's law as followed $[22,23]$ :

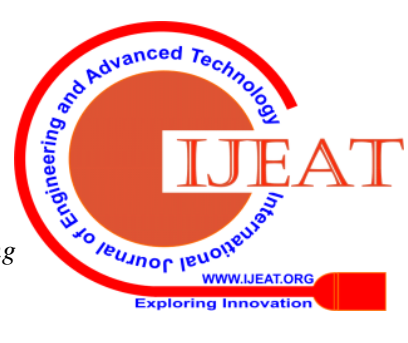


$\left\{\begin{array}{c}\sigma_{\mathrm{x}} \\ \sigma_{\mathrm{y}} \\ \tau_{\mathrm{xy}}\end{array}\right\}_{\text {isotropic }}=\left[\begin{array}{ccc}\frac{\mathrm{E}}{1-v^{2}} & \frac{v \mathrm{E}}{1-v^{2}} & 0 \\ \frac{v \mathrm{E}}{1-v^{2}} & \frac{\mathrm{E}}{1-v^{2}} & 0 \\ 0 & 0 & \mathrm{G}\end{array}\right]\left\{\begin{array}{c}\varepsilon_{\mathrm{x}} \\ \varepsilon_{\mathrm{y}} \\ \gamma_{\mathrm{xy}}\end{array}\right\}$

$\left\{\begin{array}{c}\sigma_{1} \\ \sigma_{2} \\ \tau_{12}\end{array}\right\}_{\text {otrthotropic }}=\left[\begin{array}{ccc}\frac{E_{11}}{1-v_{12} v_{21}} & \frac{v_{12} E_{11}}{1-v_{12} v_{21}} & 0 \\ \frac{v_{21} E_{22}}{1-v_{12} v_{21}} & \frac{E_{22}}{1-v_{12} v_{21}} & 0 \\ 0 & 0 & G_{21}\end{array}\right]\left\{\begin{array}{c}\varepsilon_{1} \\ \varepsilon_{2} \\ \gamma_{12}\end{array}\right\}$

Where $v$ is the Poisson's ratio and $E$ is the Young's modulus. $\sigma$ is the normal stress and $\tau$ is the shear stress. $G$ represents the shear modulus, $\gamma$ is the shear stain and tensile strain is designated as $\varepsilon$. Next, the numbers 1 and 2 indicate the direction in $i$ and $j$ respectively.

\section{B. Geometry and materials}

Specimen geometry was design similar to Rajan et al. experiment [18]. Three-dimensional model was created and meshed with 6913 nodes and 4738 elements. It was design with size equals $150 \mathrm{~mm}$ x $100 \mathrm{~mm}$. The sample was constructed from two aluminum layers and one carbon fiber/ epoxy layer. Aluminum layer thickness is $0.3 \mathrm{~mm}$. The specimen total thickness is $1.2 \mathrm{~mm}$. The impactor was drawn with a hemispherical tip had $12.7 \mathrm{~mm}$ diameter. Large impactor diameter causes short contact time, big damage and high applied stresses [29]. The materials properties were taken from the Ansys software materials library. AL2024T351 was used for metal layer. Table 1 demonstrates the material properties and Johnson Cook parameters of AL2024-T351. Moreover, unidirectional wet carbon fiber/ epoxy (230 GPa) was used for the fiber layer. The carbon fiber properties are shown in table 2. High speed tool steel material was assigned to the impactor. Its mechanical properties are illustrated in table 3. Instead of $8.16 \mathrm{~g}$ density of the high-speed tool steel, the density was calibrated. It was maximized until the impactor mas reached $3.5 \mathrm{~kg}$. The reason behind that is to match the impact velocity and the impact energy values in the experiment. The other way to achieve similar impact energy and velocity is to draw more components. However, there is no necessity to draw extra loads on the model where the simplicity is a plus in modelling and simulation.

Table- I: Material properties and Johnson Cook parameters of AL2024-T351

\begin{tabular}{|l|l|}
\hline Density $\left(\mathrm{g} / \mathrm{m}^{3}\right)$ & 2.785 \\
\hline Initial yield stress $(\mathrm{MPa})$ & 265 \\
\hline Hardening constant $(\mathrm{MPa})$ & 426 \\
\hline Hardening exponent & 0.34 \\
\hline Strain rate constant & 0.02 \\
\hline Thermal softening exponent & 1 \\
\hline Melting temperature C & 501.85 \\
\hline Reference Strain Rate(1/sec) & 1 \\
\hline Shear modulus (MPa) & 27600 \\
\hline
\end{tabular}

Table- II: Material properties UD carbon/ epoxy (230 GPa) Wet

\begin{tabular}{|l|l|}
\hline Density $\left(\mathrm{g} / \mathrm{m}^{3}\right)$ & 1518 \\
\hline Orthotropic Elasticity & \\
\hline
\end{tabular}

Retrieval Number: D8346049420/2020@BEIESP DOI: 10.35940/ijeat.D8346.049420

\begin{tabular}{|l|l|}
\hline Young's Modulus X direction (MPa) & $\begin{array}{l}12300 \\
0\end{array}$ \\
\hline Young's Modulus Y direction (MPa) & 7780 \\
\hline Young's Modulus Z direction (MPa) & 7780 \\
\hline Poisson's Ratio XY & 0.27 \\
\hline Poisson's Ratio YZ & 0.42 \\
\hline Poisson's Ratio XZ & 0.27 \\
\hline Shear Modulus XY (MPa) & 5000 \\
\hline Shear Modulus YZ (MPa) & 3080 \\
\hline Shear Modulus XZ (MPa) & 5000 \\
\hline Puck Constants & \\
\hline Compressive Inclination XZ & 0.3 \\
\hline Compressive Inclination YZ & 0.25 \\
\hline Tensile Inclination XZ & 0.35 \\
\hline Tensile Inclination YZ & 0.25 \\
\hline
\end{tabular}

Table- III: Material properties of tool steel high speed

\begin{tabular}{|l|l|}
\hline Density $\left(\mathrm{g} / \mathrm{m}^{3}\right)$ & $853^{*}$ \\
\hline Tensile yield strength $(\mathrm{MPa})$ & $2170 \mathrm{MPa}$ \\
\hline Tensile ultimate strength $(\mathrm{MPa})$ & $2390 \mathrm{MPa}$ \\
\hline
\end{tabular}

*Modified value.

Moreover, Lagrangian finite element algorithm was chosen to analyses the impact event. The impactor was aligned close to the top surface of the first aluminum layer. This is to reduce the simulation time. The friction coefficient between the impactor and CARALL 1 top layer could be set 0.2 for design validation purpose [24]. However, the contact mechanism is beyond the area of interest in this research. Hence, it was set as frictionless between all the objects. The CARALL layers and the impactor were allowed to interact. The mesh was refined until no energy error occurred. Sweep meshing method was utilized for meshing. For source or target choice, automatic thin was selected. 3D solid element was chosen. Quad or tri was assigned for free face mesh type. The model was analyzed under $22 \mathrm{C}^{\circ}$.

\section{Meshing}

Figure 4 shows the 3D drop test model after generating mesh. Solid hexahedral elements were assigned to the four objects namely the impactor, the aluminum top ply, the carbo fiber reinforce polymer (CFRP) ply and the aluminum bottom ply. The sweep mesh was implemented and located all around the impactor region.

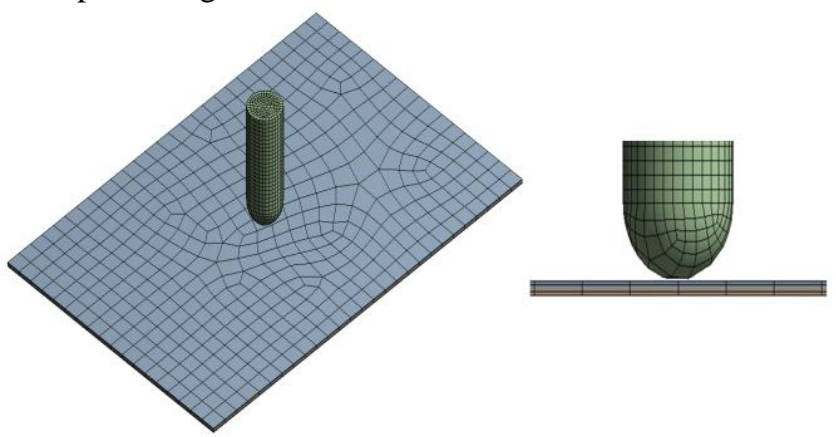

Fig. 4.Impact test 3D meshed model

D. Initial conditions

Published By:

Blue Eyes Intelligence Engineering \& Sciences Publication

(C) Copyright: All rights reserved. 
To obtain accurate results, the boundary conditions were matched with the actual experiment.

The initial velocity was $2.4 \mathrm{~m} / \mathrm{s}$. The end time was set 6.5 ms. Maximum number of cycles was given $1 \mathrm{E}+07$. Beam element solution type was chosen bending. The impactor was considered having elastic behavior. It can be chosen as a rigid body. However, after setting its behavior as a rigid body, energy error was kept occurring. Hence, it was given an elastic behavior to simulate the real-life event.

The initial velocity of the impactor could be figured out utilizing the following equation [22]:

$$
\mathrm{V}_{\mathrm{i}}=\sqrt{2 \mathrm{~g}(\mathrm{~h}-\mathrm{d})}
$$

Form the equation 5, $\mathrm{g}$ is the gravitational acceleration. $\mathrm{h}$ is the impactor height. $\mathrm{d}$ is the displacement between the impactor insert tip and the test sample.

\section{E. Meshing}

The absorbed energy by the specimen is calculated using equation number 6:

Where,

$$
\mathrm{E}_{\mathrm{abs}}=\mathrm{E}_{\mathrm{imp}}-\mathrm{E}_{\mathrm{res}}
$$

$$
E_{i m p}=\frac{1}{2} m V_{i}^{2}
$$

From equation 6 and $7 \mathrm{E}_{\text {abs }}$ is the absorbed energy, $\mathrm{E}_{\mathrm{imp}}$ is the impact energy, $E_{\text {res }}$ is the residual energy, $m$ is the impactor mass and $V_{i}$ is the initial velocity. The applied force could be obtained by triggering the external forces or differentiating impact energy/ kinetic energy - displacement curve. The absorbed energy, deformation, applied force were considered outcomes in this numerical model.

\section{RESULT AND DISCUSSION}

The result of three carbon fiber reinforced aluminum laminates are compared and discussed. The CARALL 1 represents the numerical model. CARALL 2 is the sample utilized in [18]. CARALL 3 is adopted from Yao et al. research [19]. The impact properties and damage characteristic of this material is presented in this part.

\section{A. Impact properties}

The sample penetration, maximum impact load and absorbed energy are the studied properties. Table 4 demonstrates the impact properties of CARALL 1 and CARALL 2. The maximum load of each is different. High impact load $3390 \mathrm{~N}$ is applied in the numerical analysis. In the opposite, the maximum load on the CARALL 2 was almost one-fourth of CARALL 1. It can be a consequence of different aluminum layer properties. The aluminum properties of CARALL 2 is not mentioned in [18]. Nonetheless, there is an agreement found with the result in Yao et al. work [19]. This is demonstrated in figure 9 in the absorbed energy subsection.

The maxim penetration at the maximum load is $7.7 \mathrm{~mm}$. This displacement is not far away from $5.9 \mathrm{~mm}$. There is quite agreement reached with all properties except the absorbed energy which could be linked to the fabrication procedures.

Table- IV: Material properties of tool steel high speed

\begin{tabular}{|l|l|l|}
\hline Property & $\begin{array}{l}\text { Numerical/ } \\
\text { CARALL } \\
\mathbf{1}\end{array}$ & $\begin{array}{l}\text { Experimental/ } \\
\text { CARALL 2 [18] }\end{array}$ \\
\hline Specimen thickness ( mm) & 1.2 & 1.2 \\
\hline Impact energy (J) & 10 & 10 \\
\hline Impact velocity (m/s) & 2.4 & 2.4 \\
\hline $\begin{array}{l}\text { Penetration at maximum } \\
\text { load (mm) }\end{array}$ & 7.7 & 5.9 \\
\hline Maximum load (N) & 3390 & 730 \\
\hline $\begin{array}{l}\text { Absorbed energy at } \\
\text { maximum load (J) }\end{array}$ & 10 & 6.1 \\
\hline
\end{tabular}

\section{B. Penetration}

Figure 5 shows the maximum deformation of CARALL 1 under $10 \mathrm{~J}$ impact energy. The more deformed area is the one that around the impactor tip. The maximum deformation is 7.7 $\mathrm{mm}$ as it appears in the legend. It happens at $4.2 \mathrm{~ms}$ of the impact event.

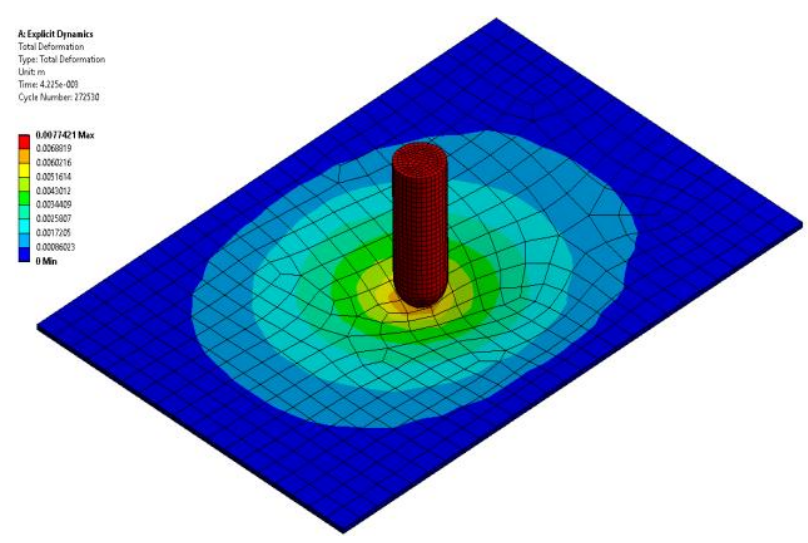

Fig. 5.Isometric view of CARALL 1 with maximum deformation.

\section{Maximum load}

Kinetic energy verses displacement curve was plotted to find out the impact load. Figure 6 shows the kinetic energydisplacement plot. From the graph underneath the kinetic energy with the value of $10 \mathrm{~J}$ is set as an initial impact energy. It decreases with the change in displacement. As the impact energy increases the laminates displacement, damage area and contact force increase [30]. At the end of the impactor travel, the kinetic energy reached zero. After that, the impactor rebound takes place.

This causes both drop in displacement and raise in kinetic energy. The decrease in displacement occurs due to the plastic reaction by the CARALL 1 while the impactor is moving upward. Beyond the plastic deformation limit, the material will not return to its original shape even if the applied load is completely removed. The energy that is consumed due to plastic work is $4.632 \mathrm{~J}$. Therefore, maximum load is the derivative of the kinetic energy with respect to displacement.

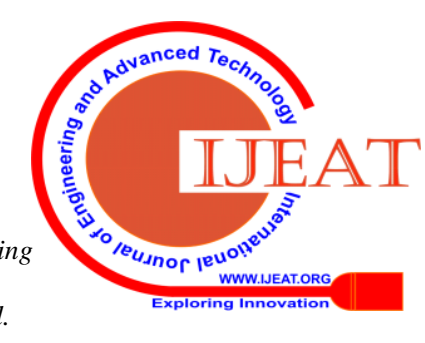




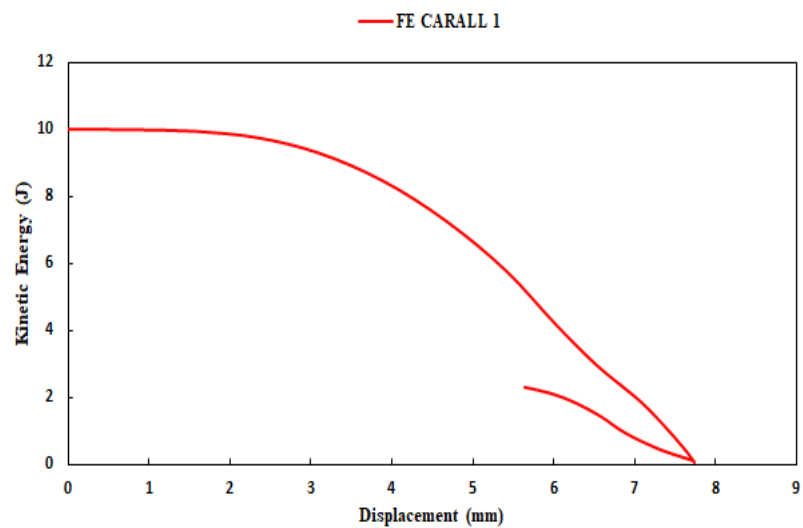

Fig. 6.Kinetic energy-displacement curve of 2/1 FE CARALL 1 under 10J

The load verses displacement curve is plotted and demonstrated in figure 7. The peak values CARALL 1 and CARALL 3 deviate from CARALL 2. The trend of CARALL 1 show fluctuation varies with the time. Oscillation of the load-time magnitude indicates failure symptoms in the material structure. The increase in force- time magnitude means an increase in bending stiffness [10]. Bottom peaks imply materials failure while exposing to impact damage. Most interestingly, before $6 \mathrm{~ms}$ all the sample show increase in the magnitude. This might be because of the resistance of the aluminum bottom layer. The end time of is each experiment is different. CARALL 1 and CARALL 3 withstand high impact load.

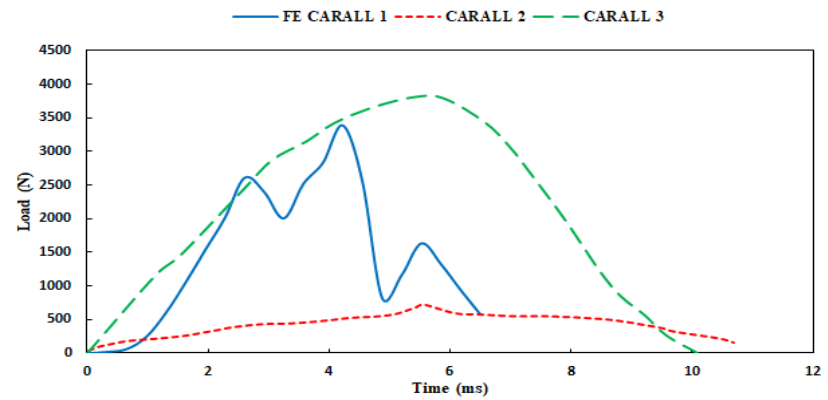

Fig. 7.Load vs time of 2/1 CARALL 1, CARALL 2 [18] and CARALL 3 [19]

The absorbed energy can be computed from the area under the load- displacement curve. As it is presented in figure 8, the CARALL 1 impact load begins with an enormous ductile behavior. Next, it shows somewhat liner increase corresponding with displacement due to elastic deformation up to $6 \mathrm{~mm}$ roughly. There is a sudden drop in the load can be related to debonding effect between the fiber and aluminum layers. Before reaching the peak load there is a sharp rise which can be interpreted as a brittle behavior of the CFRP layer. Fiber breakage occurs as a result of the reduction in bending stiffness [18]. At $7.3 \mathrm{~mm}$ perforation takes place on the CFRP layer. It happens at $4.9 \mathrm{~ms}$ and $825 \mathrm{~N}$ load which is beyond the maximum load. In the meantime, the impactor returns to the opposite direction. The load and displacement start to decrease. The change in load with respect to the time is fairly associated with the absorbed capacity of the materials. Therefore, integration of the area under the curve is equal to the absorbed energy by the material.

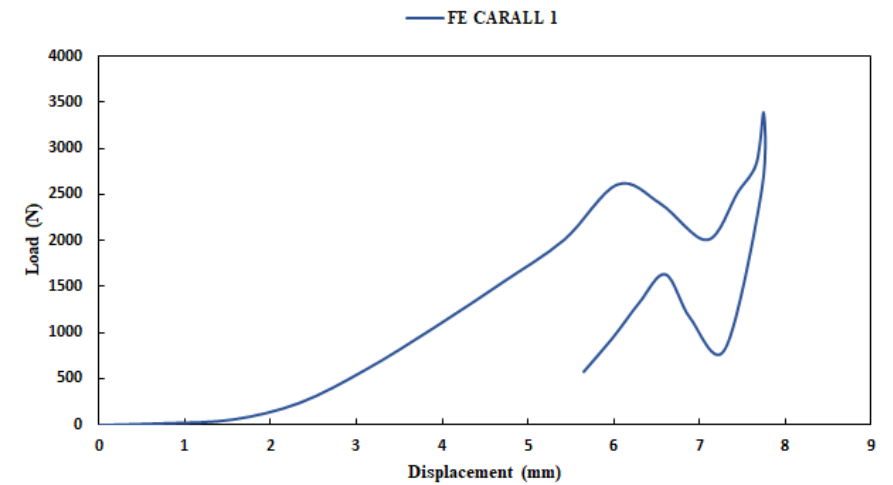

Fig. 8.Load vs displacement of 2/1 CARALL 1, CARALL 2 [18] and CARALL 3 [19]

\section{Absorbed energy}

The absorbed energy while impacting the CARALL 1 with the impact load of $3390 \mathrm{~N}$ is 10J. The absorption efficiency of which equals $100 \%$. In fact, the sample absorbed up to $10.4 \mathrm{~J}$ as it depicted in figure 9. This is slightly higher than the impact energy. Nevertheless, this increase in absorbed energy might be attributed to the inflexion that happens when the plastic wave reaches the fixed sides of the specimen [25]. It can be a result of the stored energy inside the material. At the maximum impact energy, some of the energy is stored in the FMLs whereas other return to the system and propagates to form multi different damage modes and plastic defamation on the aluminum layers [26]. There is a similarity between in the peak values. CARALL 2, on the other hand, consumes most of the energy via delamination penetration and perforation [28]. Thus, it is noticed that the absorbed energy and impact time are not dependent on the impact energy [27].

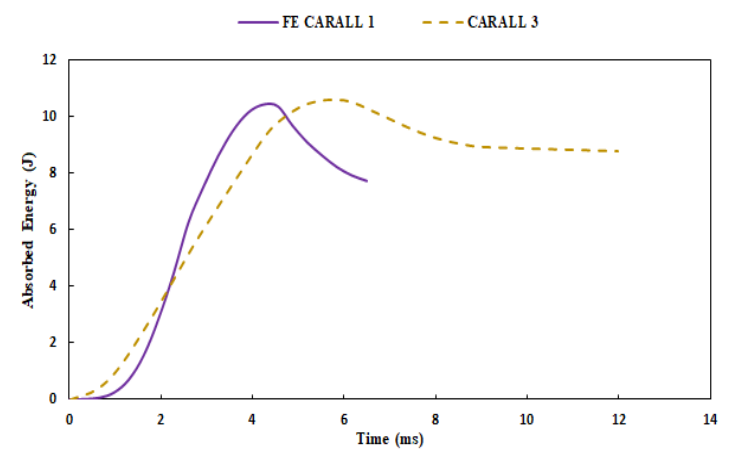

Fig. 9.Absorbed energy vs time of 2/1 CARALL 1 and CARALL 3 [19] under 10J impact energy

The absorbed energy of the material increases gradually as it deforms. CARALL 1 shows substantial energy absorption capacity. It absorbs the energy throughout delamination initiation and plastic deformation. The material noticeably begins to absorb energy after stretching almost at $1.75 \mathrm{~mm}$. The linear increase appears in the middle of the impact period. It reaches the peak level after absorbing the impact load. The reverse in the direction following by the decline in absorbed energy is due to the change in the impactor movement direction. Figure 10 illustrates the variation of the absorbed energy due to the change in displacement.

Blue Eyes Intelligence Engineering \& Sciences Publication 


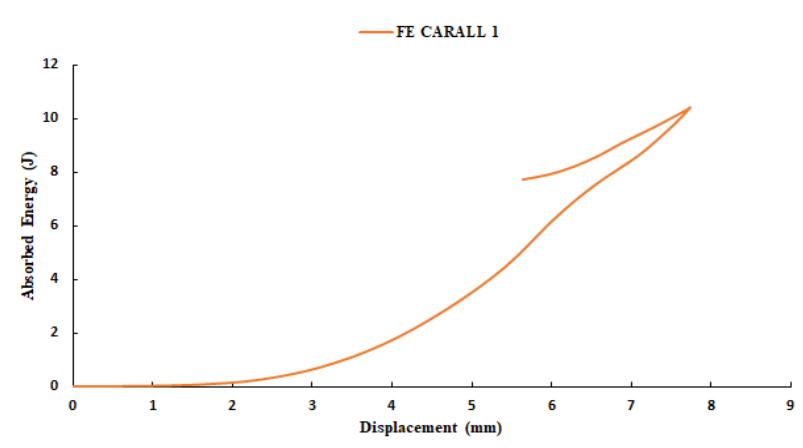

Fig. 10. Absorbed energy vs displacement of 2/1 CARALL 1 under 10J

\section{E. Damage characteristics}

The main damage mode observed among the samples is delamination. Under low impact energy most of the energy is dispelled in form of matrix damage, interfacial and inter-laminar delamination. In contrast, matrix cracking, fiber fracture, metal cracks and perforation consume the entire energy under low impact regime [19]. The delamination length is rather similar as it is shown in the cross-section view of figure 11. Carbon fiber layer conveys the energy backward which causes more damage on the back side of the sample [18]. Fiber plain orientation influences the impact resistance of the whole material [20]. Voids which initiates while hand lay-up process influence the mechanical properties [26]. Consequently, the interfacial bonding has a significant influence on the CARALL behavior.

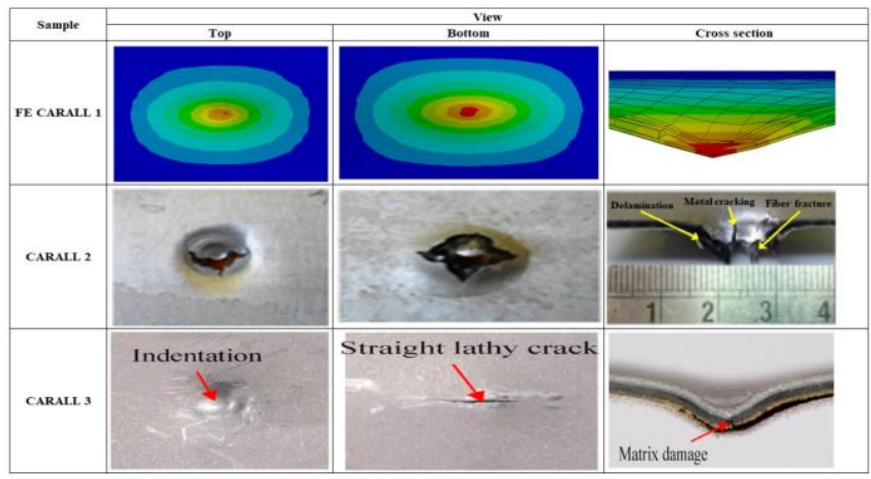

Fig. 11. Damage morphology of 2/1 CARALL 1, CARALL 2 [18] and CARALL 3 [19] under 10J

Figure 11. Damage morphology of 2/1 CARALL 1, CARALL 2 [18] and CARALL 3 [19] under 10J.

There is a high deformation on the top of the aluminum layer of the CARALL 1 as it is shown in figure 11. This is located in top right of deformed contour near to the impactor tip. The lower contour of the specimen has the highest deformation value. This is a result of reaching the high deformation magnitude. There is a fiber fracture occurs. An interfacial delamination between the lower aluminum layer and the CAFRP layer is existing. However, no metal cracking either on the top aluminum layer nor the bottom aluminum layer. The plastic deformation appears on the three samples CARALL 1, CARALL 2 and CARALL 3. A perforation phenomenon is observed on CARALL 2 while the other samples are not perforated. The specimen total thickness is not mentioned in CARLL 3 work [19]. This might be the reason a slender crack appears. Although there is sharp crack occurred on the bottom surface of CARALL2, there is no metal cracking on the top surface of the upper aluminum layer. There is a matrix fracture as well as interfacial delamination. Table 5 summaries the damage properties of CARALL 1 and CARALL 2. Area density and laminates thickness boost the energy absorption capacity and impact resistance [27].

Table- I: Damage properties of CARALL1 and CARALL2

\begin{tabular}{|l|l|l|}
\hline Property & $\begin{array}{l}\text { Numerical/ } \\
\text { CARALL 1 }\end{array}$ & $\begin{array}{l}\text { Experimental/ } \\
\text { CARALL 2 [18] }\end{array}$ \\
\hline Perforation & Fiber layer only & Full perforation \\
\hline Delamination & Yes & Yes \\
\hline Metal crack & No & Yes \\
\hline Fiber fracture & Yes & Yes \\
\hline
\end{tabular}

\section{F. CARALL 1 morphology}

FE simulation provides exclusive features to observe complex mechanisms. Figure 12 depicts the morphology of the CARALL 1 layers independently. The highest deformation appears on the Al bottom layers. The Al top layer shows the lowest displacement value as it is located at the top position of the specimen. This variance in deformation is caused by the transverse shear throughout the layers thicknesses [26]. There is a perforation in the fiber layer. The general mechanisms occur under impact are aluminum yielding at the impactor tip, large strain causes fiber facture and aluminum cracking related to perforation of the CARALL layers [31]. The failure of the inner layer causes a degradation in impact resistance which cannot be easily seen by the naked eye.

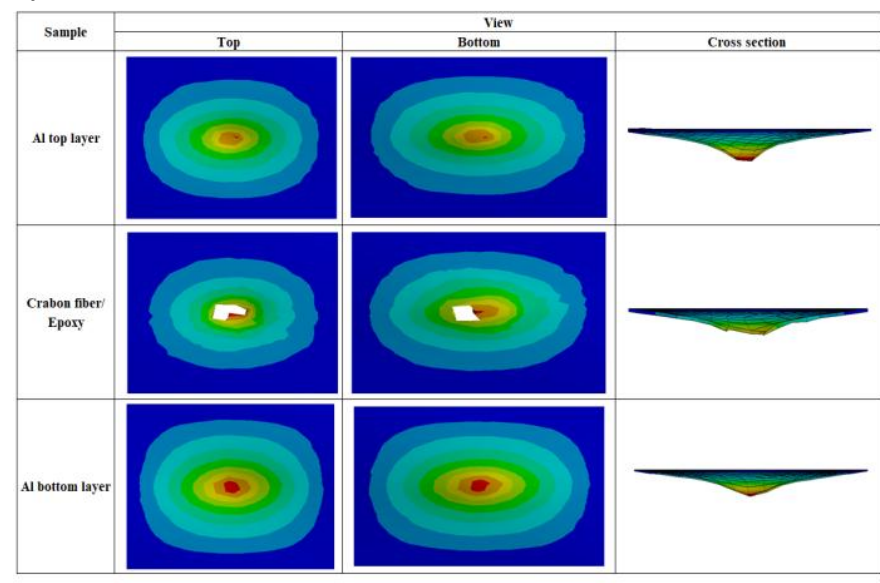

Fig. 12. Damage morphology of 2/1 CARALL 1 metal and fiber layers under $10 \mathrm{~J}$

\section{CONCLUSION}

A 3D numerical model was developed based on finite element method to simulate carbon fiber reinforced aluminum laminates under low velocity impact. The model was validated with two experiments found in the literature. Impactor velocity was set $2.4 \mathrm{~m} / \mathrm{s}$. The impact energy was 10 J. The maximum impact load reached $3390 \mathrm{~N}$. The material defamation was $7.7 \mathrm{~mm}$. Perforation took place in the CFRP layer whereas the aluminum top and bottom layers did not show any metal fracture.

\section{Published By:}

Blue Eyes Intelligence Engineering \& Sciences Publication

(C) Copyright: All rights reserved.

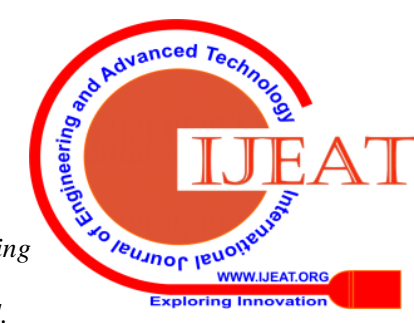


Interfacial delamination and fiber fracture occurred in CARALL 1. In addition, CARALL 2 diverged in terms of the impact load. CARALL 3 had quite similarity in the impact energy and absorbed energy values. There was an increase in the impact energy attributed to the fixture mechanism of the sample. This is recommended to future investigation. The relationship between the impact energy and residual energy can be considered as well. The FE modelling is an effective tool for determining the impact properties and damage characteristics of the CARALL material.

\section{REFERENCES}

1. Carrillo JG, Cantwell WJ. Mechanical properties of a novel fiber-metal laminate based on a polypropylene composite. Mechanics of Materials 2009;41:828-38.

2. Wu G, Yang J-M. The mechanical behavior of GLARE laminates for aircraft structures. JOM 2005;57:72-9.

3. Sinmazçelik T, Avcu E, Bora MÖ, Çoban O. A review: Fibre metal laminates, background, bonding types and applied test methods. Materials \& Design 2011;32:3671-85.

4. Alderliesten R, Homan J. Fatigue and damage tolerance issues of Glare in aircraft structures. International Journal of Fatigue 2006;28:1116-23.

5. Remmers JJC, de Borst R. Delamination buckling of fibre-metal laminates. Composites Science and Technology 2001;61:2207-13.

6. Fan J, Cantwell W, Guan Z. The low-velocity impact response of fiber-metal laminates. Journal of Reinforced Plastics and Composites 2011;30:26-35.

7. Morinière F, Alderliesten R, Tooski M, Benedictus R. Damage evolution in GLARE fibre-metal laminate under repeated low-velocity impact tests. Open Engineering [Internet] 2012 [cited 2020 Mar 30];2. Available

from:

http://www.degruyter.com/view/j/eng.2012.2.issue-4/s13531-012-001 9-z/s13531-012-0019-z.xml

8. Abdullah MR, Cantwell WJ. The high-velocity impact response of thermoplastic-matrix fibre-metal laminates. The Journal of Strain Analysis for Engineering Design 2012;47:432-43.

9. Vlot A, Krull M. Impact Damage Resistance of Various Fiber Metal Laminates. J. Phys. IV France 1997;07:C3-1045-C3-1050.

10. Bieniaś J, Jakubczak P, Surowska B, Dragan K. Low-energy impact behavior and damage characterization of carbon fiber reinforced polymer and aluminum hybrid laminates. Archives of Civil and Mechanical Engineering 2015;15:925-32.

11. Erkliğ A, Bulut M. Experimental investigation on tensile and Charpy impact behavior of Kevlar/S-glass/epoxy hybrid composite laminates. Journal of Polymer Engineering 2017;37:177-84.

12. Moussavi-Torshizi SE, Dariushi S, Sadighi M, Safarpour P. A study on tensile properties of a novel fiber/metal laminates. Materials Science and Engineering: A 2010;527:4920-5.

13. Vogelesang LB, Vlot A. Development of ®bre metal laminates for advanced aerospace structures. Journal of Materials Processing Technology 2000;5.

14. Kawai M, Hachinohe A, Takumida K, Kawase Y. Off-axis fatigue behaviour and its damage mechanics modelling for unidirectional fibre-metal hybrid composite: GLARE 2. Composites Part A: Applied Science and Manufacturing 2001;32:13-23.

15. Ha-Minh C. Numerical analysis of the ballistic performance of textile fabrics. In: Advanced Fibrous Composite Materials for Ballistic Protection. Elsevier; 2016. page 457-500.

16. Mousavi MV, Khoramishad $\mathrm{H}$. The effect of hybridization on high-velocity impact response of carbon fiber-reinforced polymer composites using finite element modeling, Taguchi method and artificial neural network. Aerospace Science and Technology 2019;94:105393.

17. Yu G-C, Wu L-Z, Ma L, Xiong J. Low velocity impact of carbon fibe aluminum laminates. Composite Structures 2015;119:757-66.

18. Rajan BMC, Kumar A, Sornakumar T, Kumaar AS. Impact Response and Damage Characteristics of Carbon Fibre Reinforced Aluminium Laminates (CARAL) under Low Velocity Impact Tests. Materials Today: Proceedings 2018;5:20070-7.

19. Yao L, Wang C, He W, Lu S, Xie D. Influence of impactor shape on low-velocity impact behavior of fiber metal laminates combined numerical and experimental approaches. Thin-Walled Structures 2019;145:106399.
20. Li P, Zhao M, Wan X. Finite element analysis of configuration and fiber orientation effects on fiber metal laminates subjected to low velocity impact [Internet]. In: 2017 8th International Conference on Mechanical and Aerospace Engineering (ICMAE). Prague, Czech Republic: IEEE; 2017 [cited 2020 Jan 31]. page 222-7.Available from: http://ieeexplore.ieee.org/document/8038646/

21. Logan DL. A first course in finite element method: sixth edition. Si edition. Mason, OH: Cengage Learning; 2016.

22. Tanadrob K, Suvanjumrat C. Composite Material Modeling under Drop Weight Impact Test Using Finite Element Analysis. MSF 2017;889:3-8

23. Nettles AT. Basic mechanics of laminated composite plates. 1994;

24. 24. Vidyapeetham AV. Numerical simulation of low velocity impact analysis of fiber metal laminates. Mechanics and Mechanical Engineering 2016;20:515-30.

25. Luo G, Xue P. Investigations on the mechanism and behavior of dynamic energy absorption of metal foam. Lat. Am. j. solids struct. [Internet] 2018 [cited 2020 Mar 31];15. Available from: http://www.scielo.br/scielo.php?script=sci_arttext\&pid=S1679-78252 018000600501\&lng=en\&tlng=en

26. Rajkumar GR, Krishna M, Murthy HNN, Sharma SC, Mahesh Krv. Effect Of Low Velocity Repeated Impacts On Property Degradation Of Aluminum-Glass Fiber Laminates. International Journal of Engineering Science and Technology 2011;3:11.

27. Zhou J, Guan Z, Cantwell W. Numerical modelling of perforation impact damage of fibre metal laminates. :12.

28. Dhaliwal GS, Newaz GM. Effect of Layer Structure on Dynamic Response and Failure Characteristics of Carbon Fiber Reinforced Aluminum Laminates (CARALL). J. dynamic behavior mater. 2016;2:399-409.

29. Kurşun A, Şenel M, Enginsoy HM, Bayraktar E. Effect of impactor shapes on the low velocity impact damage of sandwich composite plate: Experimental study and modelling. Composites Part B Engineering 2016;86:143-51.

30. He J, He L, Yang B. Analysis on the impact response of fiber-reinforced composite laminates: an emphasis on the FEM simulation. Science and Engineering of Composite Materials 2019;26:1-11.

31. Zhu S, Chai GB. Impact of Aluminum, CFRP Laminates, Fibre-Metal Laminates and Sandwich Panels [Internet]. In: Patterson E, Backman D, Cloud G, editors. Composite Materials and Joining Technologies for Composites, Volume 7. New York, NY: Springer New York; 2013 [cited 2020 Feb 3]. page 199-205.Available from: http://link.springer.com/10.1007/978-1-4614-4553-1_21

\section{AUTHORS PROFILE}

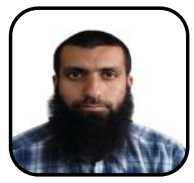

Eng. Khalid M. Algadah The author has received his BEng of Mechanical engineering in 2009 from Riyadh College of Technology (RCT). He obtained his PG dip. of Automotive and Motorsport engineering in 2014 from Brunel University London. Currently, he is doing his MSc in Mechanical engineering at Qassim university. His research interest includes systems modelling and simulation, materials engineering, finite element analysis, fracture mechanics, automotive engineering, control systems. He is a member of American Society of Mechanical Engineers (ASME). He is also one of the Institution of Mechanical Engineers (IMechE) members.

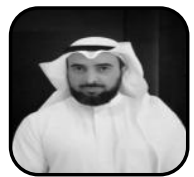

Prof. Abdulaziz S. Alaboodi completed his $\mathrm{PhD}$ from King Fahd University for Petroleum and Minerals, Saudi Arabia. He is a Professor at Qassim University. He has over 40 Multi-national Journal and Conference papers to his credit. 